\title{
A GEOMETRIA CONTIDA NOS SÍMBOLOS
}

\author{
GEOMETRY CONTAINS SYMBOLS
}

\author{
Apresentação: Comunicação Oral \\ Werick de Sousa Castro ${ }^{1}$; Joziel Machado da Silva ${ }^{2}$; Tiago Gomes Sousa da Silva ${ }^{3}$ Cariane \\ Gomes Assunção ${ }^{4}$; Francismar Holanda ${ }^{5}$
}

DOI: $\underline{\text { https://doi.org/10.31692/2358-9728.VCOINTERPDVL.2018.00011 }}$

\section{Resumo}

O presente artigo é resultado da aplicação de uma atividade em caráter de pesquisa realizada em uma turma de $3^{\circ}$ ano do ensino médio da Unidade Escolar Benjamin Baptista com a participação de alunos bolsistas do Pibid em 2017, que objetivou trabalhar interdisciplinarmente conceitos de Geometria Plana ligados à construção de símbolos presentes no cotidiano dos alunos. O Desenho Geométrico é um capítulo da Geometria que, com o auxílio de dois instrumentos, régua e o compasso, se propõe a resolver graficamente problemas de natureza teórica e prática. O ensino do desenho é essencial para que não haja o bloqueio das capacidades de planejar, projetar ou abstrair, estabelecendo assim uma relação contínua entre a percepção visual e o raciocínio espacial. Além disso, o Desenho é a matéria mais adequada para incutir nos jovens bons hábitos de capricho, cuidado com os instrumentos de trabalho, habilidade manual, entre outras. Após pesquisar sobre fatos importantes relacionados aos símbolos estudados, os alunos desenharam os símbolos baseados nas técnicas de construção de figuras geométricas. Em seguida, todos os trabalhos foram apresentados para a comunidade escolar e posteriormente representaram a escola no III Circuito de Ciências das Escolas da Rede Pública. Pode-se perceber a preocupação por parte dos alunos em geral, em construir desenhos de qualidade, garantindo a eles uma melhora nas suas habilidades, principalmente na atenção, coordenação motora e concentração. Observouse também que os alunos conseguiram se sobressair durante as atividades, sanando algumas deficiências relacionadas aos conceitos de figuras geométricas, tais como bissetriz, mediatriz, mediana, retas paralelas, lugar geométrico e construção de ângulos com o compasso.

Outro aspecto que pudemos observar foi a rápida compreensão dos alunos em associar os conceitos estudados com diversas situações presentes no seu cotidiano e a relação que matemática mantém com as suas vidas.

\footnotetext{
${ }^{1}$ Licenciatura em Matemática, Ifpi Teresina Central, werickcastro83@gmail.com

${ }^{2}$ Licenciatura em Matemática, Ifpi Teresina Central, jozielm2@gmail.com

${ }^{3}$ Licenciatura em Matemática, Ifpi Teresina Central, tiagomat07@gmail.com

${ }^{4}$ Licenciatura em Matemática, Ifpi Teresina Central, carianegomes96@gmail.com

${ }^{5}$ Mestre, Ifpi Teresina Central, frholanda@ifpi.edu.br
} 
Palavras-Chave: Desenho Geométrico, Símbolos, Interdisciplinaridade.

\begin{abstract}
The present article is the result of the implementation of a research activity carried out in a 3rd year high school class of the Benjamin Baptista School Unit with the participation of Pibid scholarship students in 2017, which aimed to work interdisciplinary concepts of Flat Geometry related to construction of symbols present in the students' daily life. The Geometric Drawing is a chapter of Geometry which, with the help of two instruments, ruler and compass, proposes to graphically solve problems of a theoretical and practical nature. The teaching of drawing is essential so that there is no blocking of the capacities to plan, design or abstract, thus establishing a continuous relationship between visual perception and spatial reasoning. In addition, the Drawing is the most appropriate material to instill good habits in the young of caprice, care with the tools of work, manual ability, among others. After researching important facts related to the symbols studied, the students designed the symbols based on the techniques of construction of geometric figures. Then all the works were presented to the school community and later they represented the school in the III Circuit of Sciences of the Schools of the Public Network. It can be noticed the concern on the part of the students in general, to build quality drawings, guaranteeing to them an improvement in their abilities, mainly in the attention, motor coordination and concentration. It was also observed that the students were able to excel during the activities, healing some deficiencies related to the concepts of geometric figures, such as bisector, perpendicular bisector, median, parallel lines, geometric locus and construction of angles with the compass.

Another aspect that we could observe was the students' rapid comprehension in associating the concepts studied with diverse situations present in their daily life and the relation that mathematics maintains with their lives.
\end{abstract}

Keywords: geometric draw, symbols, interdisciplinarity.

\title{
Introdução
}

Diante da dificuldade dos alunos em compreender como a matemática está presente em seu dia-a-dia, torna-se importante desenvolver atividades práticas que possam despertar a curiosidade e a vontade de descobrir situações do seu cotidiano em que a matemática é perceptível. Para isso, desenvolveu-se essa atividade utilizando o desenho geométrico nas turmas de $3^{\circ}$ ano do ensino médio no turno da tarde da Unidade Escolar Benjamim Baptista com o objetivo de mostrar a esses alunos que a matemática está envolvida em diversas áreas de sua vida desde situações simples até as mais complexas. 


\section{Objetivos:}

Promover a interdisciplinaridade, mencionando fatos históricos relacionados com o conteúdo, conceitos físicos e a matemática aplicada no problema, fazendo com que o aluno associe o saber sobre vários aspectos;

Estimular o aluno à prática experimental, utilizando elementos do desenho geométrico como meio de praticar o que está sendo ensinado;

Mostrar ao aluno que a matemática está presente em seu cotidiano e que o conhecimento adquirido lhe proporcionará novas descobertas.

\section{Fundamentação Teórica}

A reflexão a respeito dos signos (símbolos) não nasceu recentemente, remonta à antiguidade grega e o termo semiótica (em grego sêmeiôtikê) advém de sêmion, "signo". As imagens estão divididas em dois domínios: o domínio das representações visuais - desenhos,

pinturas, gravuras, fotografias, imagens cinematográficas, televisivas, holográficas e infográficas, e o domínio das representações mentais - visões, fantasias, imaginações, modelos.

$\mathrm{Na}$ nova perspectiva de ensino-aprendizagem, onde o conhecimento é construído a partir de muita investigação e exploração e a formalização é simplesmente o coroamento deste trabalho, a técnica de leitura de imagem é perfeitamente aplicável.

O Desenho Geométrico é um capítulo da Geometria que, com o auxílio de dois instrumentos, régua e o compasso, se propõe a resolver graficamente problemas de natureza teórica e prática. Lima (1991) considera os desenhos das figuras geométricas parte importantíssima para a compreensão, a fixação e a imaginação criativa. Ele acha fundamental que o estudante por si só desenhe a figura, procurando caminhos, imaginando construções, pesquisando interconexões, forçando o raciocínio, e exercitando a mente.

De acordo com Kalter (op. cit.) o ensino do desenho é essencial para que não haja o bloqueio das capacidades de planejar, projetar ou abstrair, estabelecendo assim uma relação contínua entre a percepção visual e o raciocínio espacial. Para Dante (2002), tudo o que nos rodeia lembra formas geométricas, elas são as mais diversas e podem ser observadas nas artes, na natureza, nas construções, etc. e segundo Marmo \& Marmo (1994), o Desenho é a matéria 
mais adequada para incutir nos jovens bons hábitos de capricho, cuidado com os instrumentos de trabalho, habilidade manual, entre outras. Lembra também que o Desenho Geométrico nos ensina a linguagem gráfica que é uma forma concisa, precisa e universal de comunicar e expressar ideias, não estudá-lo torna-se uma falha no ensino.

\section{Metodologia}

Trata-se de uma pesquisa qualitativa do tipo experimental voltada à educação realizada com estudantes de uma turma do $3^{\circ}$ ano do ensino médio matriculados na Unidade Escolar Benjamim Baptista.

\section{MATERIAL}

- Lápis;

- Borracha;

- Régua;

- Compasso;

- Pincéis;

- Cartolina;

\section{PROCEDIMENTOS}

Primeiramente, será apresentado aos alunos o material que servirá como base para a realização da atividade; trata-se de uma apostila que apresenta cinco símbolos distintos que são muito conhecidos, que trazem conceitos/valores representativos diversificados. Ao lado de cada símbolo são mostrados passos de como desenha-lo geometricamente com medidas de referência e utilizando régua e compasso. Esse material foi utilizado durante uma oficina do evento XIII SEMAFIS, organizado pelo Instituto Federal do Piauí/ Campus Teresina central. 
Figura 1- Material de Apoio da Oficina "O Desenho Geométrico Contido nos Símbolos". Fonte: IFPI Teresina Central - XIII Semafis

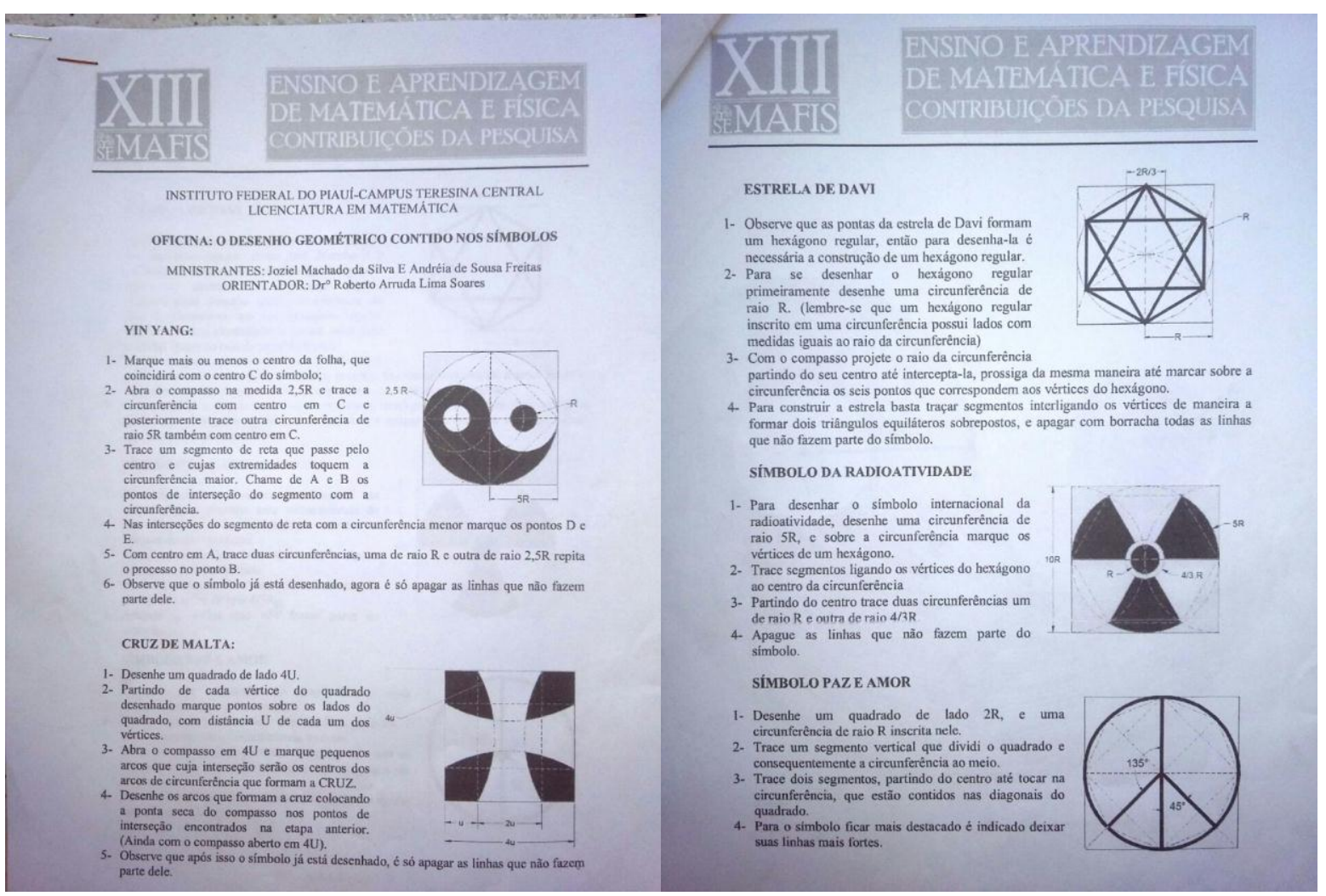

A turma será dividida em quatro grupos e cada um dos grupos será responsável por um símbolo. Após a divisão dos grupos, cada um deles fará uma pesquisa histórica sobre o referido símbolo que mostre como o símbolo foi criado, qual a sua finalidade, que tipo de informações ele traz nos seus aspectos culturais, fatos importantes e curiosidades.

Por fim, as principais informações pesquisadas serão colocadas em uma cartolina, bem como o símbolo a ser desenhado e os procedimentos para a construção da figura. Cada trabalho será apresentado pelos grupos em seminários na sala de aula e posteriormente serão expostos no pátio da escola durante um evento para que toda a comunidade escolar possa apreciá-los.

\section{Resultados e Discussão}

As pesquisas realizadas pelos alunos nos trouxeram os seguintes resultados:

1.Segundo a compreensão chinesa do mundo, a terra é composta por duas forças: yang - ser masculino e yin - ser feminino. No ano de 1850 um filósofo de nome Ralph Ermeson, 
em sua análise a respeito da filosofia oriental, expôs minuciosamente que o yin e o yang concentravam-se em um ou mais pontos, ou em duas ou mais posições opostas, como por exemplo, em uma ação ou reação,; se houvesse escuridão automaticamente haveria a luz, o mesmo acontecendo com o calor e o frio, o masculino e o feminino, assim como nas forças centrífugas que tendem a se afastar do centro e nas forças centrípetas que tendem a se aproximar do centro.

FOTO 1- Desenho do yin-yang. Fonte: própria.

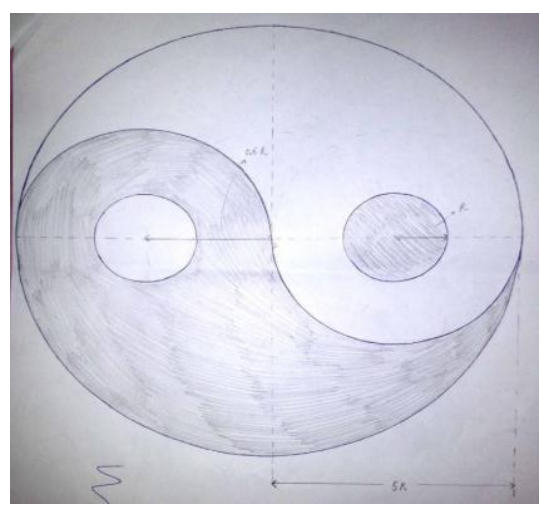

FOTO 2 - Apresentação do grupo 1. Fonte: própria.

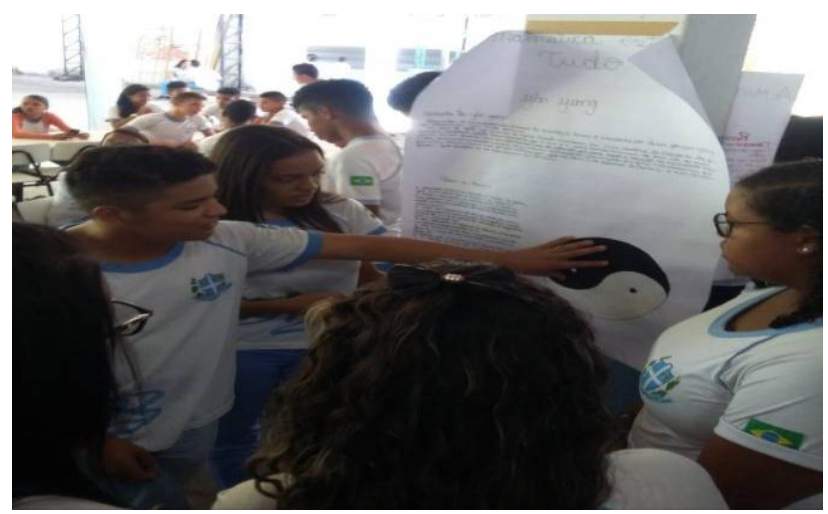

2.O símbolo da estrela de Davi era desenhado ou encravado sobre os escudos dos guerreiros do exército do Rei Davi. Esta tradição teve origem no fato de o nome hebraico para Davi ser escrito originalmente por três letras do alfabeto hebraico. A letra daleth tinha uma forma triangular no alfabeto hebraico usado até então uma variação do alfabeto fenício.

FOTO 3 - Desenho da Estrela de Davi. Fonte: própria.

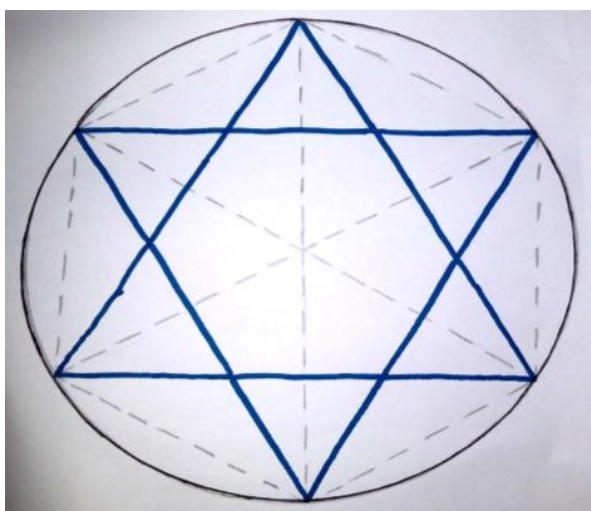

FOTO 4 - Apresentação do grupo 2. Fonte:própria.

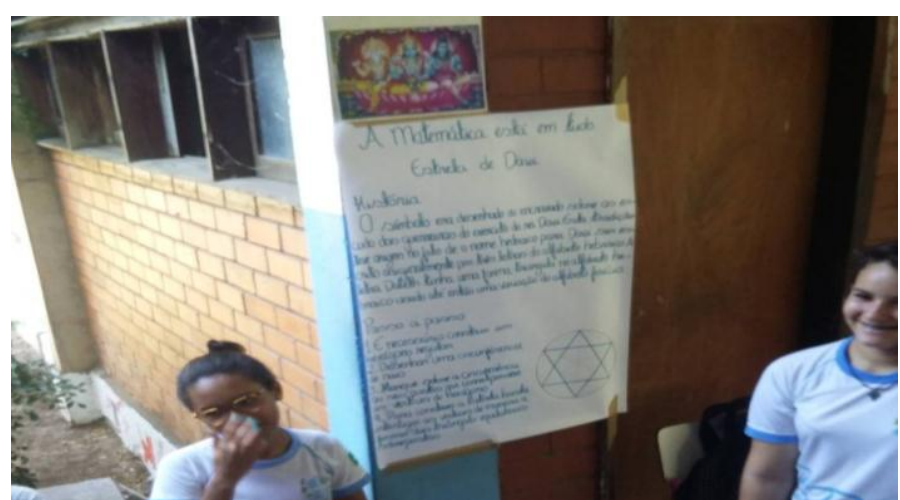

3.O desenho é chamado trifólio. Ele é usado internacionalmente para indicar a presença de radiação. Nome também dado ao trevo de três folhas. Segundo o físico americano Paul Frame, da Universidade de Michigan, o desenho foi rabiscado pela primeira vez em 
1946. As três pás representam a atividade que erradia dela.

FOTO 5 - Desenho radioatividade.

Fonte: própria.

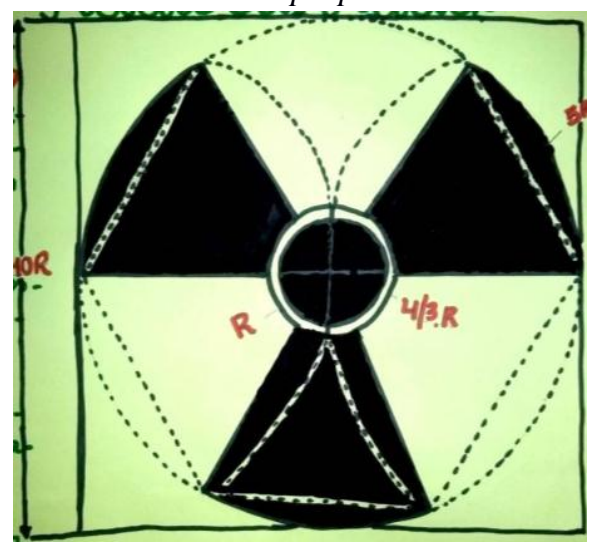

FOTO 6 - Apresentação do grupo 3. Fonte: própria.

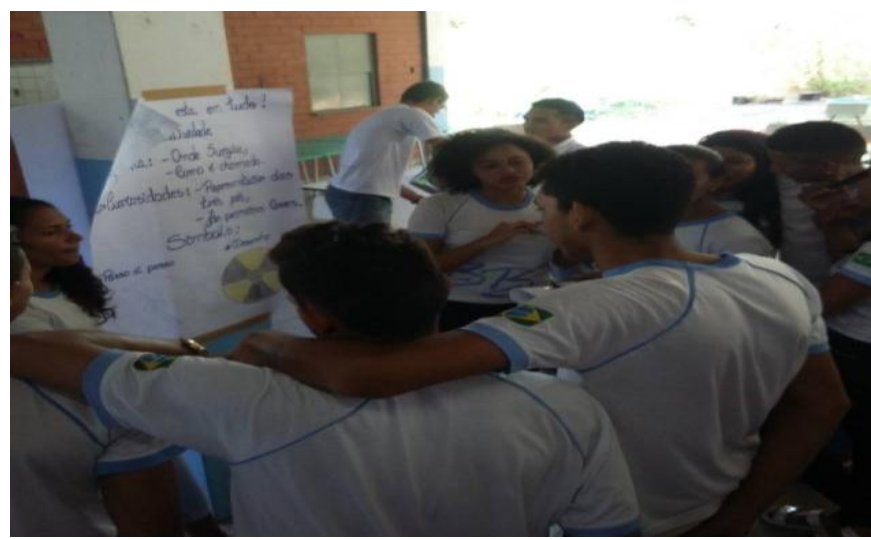

4.Criado pelo artista britânico Gerald Herbert Holtom em 1958, na Inglaterra para representar o desespero que ele sentia diante do mundo, durante grandes protestos, lutando contra a construção de armas nucleares. Este símbolo representa a união das letras "n" e "d", que remete a junção das palavras (desarmamento nuclear) e o círculo em volta representa a Terra.

FOTO 7 - Desenho Paz e Amor. Fonte: própria.

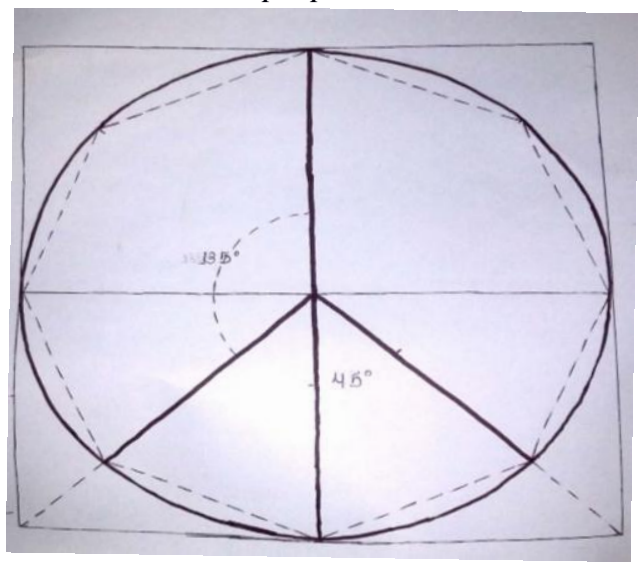

FOTO 8 - Apresentação do grupo 4. Fonte: própria.

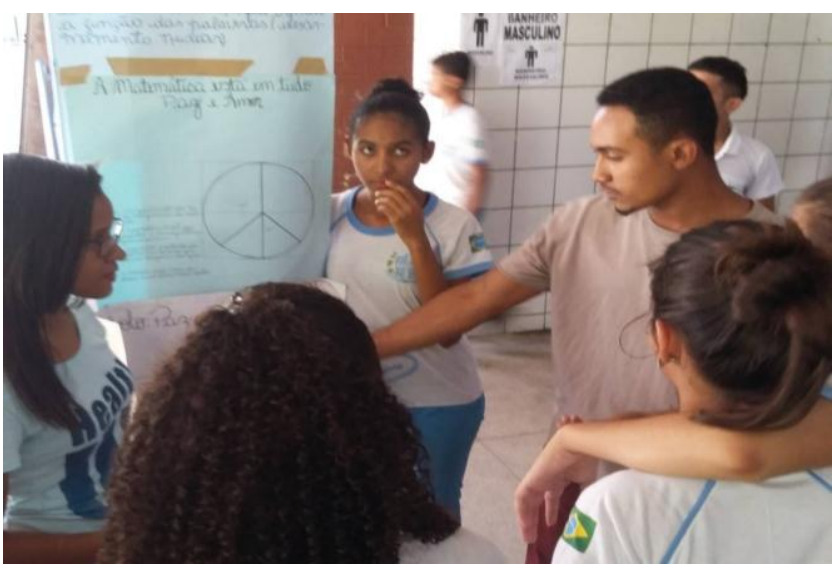

\section{Conclusões}

Podemos destacar ao final das atividades a preocupação por parte dos alunos em geral, em construir desenhos de qualidade, garantindo a eles uma melhora nas suas habilidades, principalmente na atenção, coordenação motora e concentração. Tal esforço trouxe uma 
recompensa, que foi a inscrição do trabalho no III Circuito de Ciências das Escolas da Rede Pública de Ensino do Piauí, que após ter sido selecionado na etapa local competiu com as escolas da $4^{a}$ GRE - Gerência Regional da educação. Observou-se também que, apesar dos alunos terem pouco contado com o desenho geométrico na sua prática, conseguiram se sobressair durante as atividades, sanando algumas deficiências relacionadas aos conceitos de figuras geométricas, tais como bissetriz, mediatriz, mediana, retas paralelas, lugar geométrico e construção de ângulos com o compasso.

Outro aspecto que pudemos observar foi a rápida compreensão dos alunos em associar os conceitos estudados com diversas situações presentes no seu cotidiano e a relação que matemática mantém com as suas vidas.

\section{Referências}

ITACARAMBI, Ruth Ribas - Minicurso: A GEOMETRIA NOS SÍMBOLOS, LOGOTIPOS E LOGOMARCAS, Encontro Nacional de Educação Matemática (ENEM), São Paulo, 2016;

OLIVEIRA, Clézio Lemes - Artigo: IMPORTÂNCIA DO DESENHO GEOMÉTRICO, Universidade Católica de Brasília, DF;

SILVA, Joziel M. - Minicurso: O DESENHO GEOMÉTRICO CONTIDO NOS SÍMBOLOS, XIII Semana de Matemática e física (SEMAFIS) /IFPI - Teresina Central, Piauí, 2017.

SILVA, Juliana Cruz - Artigo: A ARTE COMO ALIADA NO ENSINO DA GEOMETRIA PLANA, Universidade Católica de Brasília, DF; 